\title{
Cães E PRECONCEITO NA ÁFRICA DO SUL: UM DÍLLLOGO ENTRE LITERATURA E ETNOGRAFIA*
}

\author{
Antonádia Borges** \\ Universidade de Brasília - Brasil
}

Resumo: Coadunando fiç̧ão literária e etnográfica, o presente artigo toma como inspiração o romance Disgrace de Coetzee, os chamados discursos de ódio atribuídos a Julius Malema e a experiência dos moradores de fazenda na região de Kwazulu-Natal para problematizar disputas entre "ideais de existência" que têm cães como mediadores. O objetivo aqui é atentar para o efeito epistemológico que o entendimento das trocas de insultos por meio dos animais pode ter sobre nossa compreensão do racismo na África do Sul e alhures, e sobre o papel da antropologia a esse respeito.

Palavras-chave: África do Sul, humanos e animais, John Maxwell Coetzee, racismo.

Abstract: Bringing together a novel (Disgrace, by Coetzee), Julius Malema's socalled hate speeches and farm-dwellers eviction experiences in Kwazulu-Natal, the paper aims to analyse disputes on "existence ideals" that entail dogs as mediators in South Africa and beyond. Insults through animals challenge our understanding of persistent racism and offer an opportunity to an anthropological self-critic.

Keywords: humans and animals, John Maxwell Coetzee, racism, South Africa.

\footnotetext{
* O presente artigo desenvolve argumentos esboçados no encontro anual da Anpocs em 2014, em mesa sobre a experiência etnográfica, a literatura e as relações entre o conhecimento, a arte e seus efeitos políticos, da qual participaram Ana Lúcia Modesto, Regina Coeli Machado e Suely Kofes, a quem sou profundamente grata. $\mathrm{O}$ argumento também se beneficiou dos comentários colhidos no encontro do Grupo de Estudos de Teoria Antropológica (Gesta). Agradeço à Mariza Peirano, pela minuciosa leitura, e ao parecerista anônimo, pelas edificantes sugestões.

** Contato: antonadia@gmail.com
} 
Antonádia Borges

A dog is social history that can bark.

Sandra Swart

Em seu clássico de 1964, Leach (2000) voltava-se para os insultos que, aludindo a qualidades animais, tornavam tangível a separação entre quem enunciava e quem era objeto do achincalhe: uns humanos, outros animais. O principal interesse de Leach era demonstrar por uma via aparentemente inusitada o quanto a segmentação do real em unidades discretas se fazia por meio da produção de interstícios, de espaços vazios:

If $[\ldots]$ we are only able to perceive the environment as composed of separate things by suppressing our recognition of the non-things which fill the interstices, then of course what is suppressed becomes especially interesting [...] the gap $[\ldots]$ is filled in with tabooed ambiguity[...] these marginal, ambiguous creatures are specifically credited with the power of mediating. (Leach, 2000, p. 330 , grifo meu).

Contemporaneamente, a literatura que recebe no mais das vezes a alcunha de pós-humanista também aposta no rendimento analítico da noção de mediador. Nela vemos o termo ser acionado com o fim de superar preceitos iluministas, próprios de abordagens pouco afeitas aos efeitos desestabilizadores que a atenção à performatividade traz (Law, 2004). Sua intenção parece não ser preencher buracos - os interstícios, de que nos fala Leach -, mas indicar os limites dos conhecimentos baseados na separação entre sujeitos e objetos, sujeitos e sujeitos e entre objetos e objetos. Em suma, trata-se de propostas interessadas em demonstrar a importância de se atentar para o discurso ou as palavras não como representações de ideias, mas como efeitos de reticularidade (Sá, 2013).

Assumindo tal postura, neste artigo tomarei ficção literária e ficção etnográfica como matérias de igual rendimento, sem equipará-las em suas supostas qualidades imanentes, na medida em que tal oposição nem sequer se faz pertinente para o propósito mais geral de estudar justamente seus efeitos. O presente texto tem como objeto de reflexão discursos de ódio entre humanos que se agridem por meio de analogias envolvendo certas propriedades associadas aos cachorros, a fim de tornar bestializadas as pessoas-alvo da comparação. 
$\mathrm{Na}$ África do Sul contemporânea, pessoas são comparadas a cães para se afirmar ora que são animalizadas como cachorros, ora para dizer que elas são menos humanas que esses bichos. A eficácia das qualidades selecionadas para a agressão parece-nos ser garantida por um não dito, ou seja, por uma enunciação que alude de forma tangencial a um conjunto de predicados ausente dentre os humanos considerados por isso "menos que gente", as quais são, concomitantemente, qualidades supostas como da "natureza humana" percebidas nos animais e que os tornariam passíveis de afeto e respeito. ${ }^{1} \mathrm{O}$ objetivo aqui é atentar para o efeito epistemológico que tal entendimento das trocas de insultos por meio dos animais pode ter sobre nossa compreensão do racismo na África do Sul e alhures, e sobre o papel da antropologia a esse respeito.

Os efeitos das acusações que lançam mão dos cães não derivam apenas da precisão de sentido das palavras empregadas nos discursos de ódio, mas especialmente de sua obliteração seletiva - da obliteração do que conecta. Por ora, é pertinente explicitar a perspectiva pragmática por mim adotada nesta análise, com ecos em produções distintas, acerca da eficácia de insultos que se apoiam em animais como terceiro. ${ }^{2}$ A exemplo do que dizem autoras como Favret-Saada (1977) e Peirano (2006), palavras "fazem", atuam, não pelo seu sentido "preciso". "Não ditos" podem tanto quanto enunciados explícitos, afinal o fato de não os vermos/escutarmos não significa que não existam, que não tenham implicações.

\section{Cães são os Outros}

Refletir sobre a dupla valência dos cachorros nos discursos racistas, na sua triangulação com brancos e negros, tem algumas consequências. A primeira delas diz respeito à constatação de que nem cães nem pessoas seriam dotados de propriedades intrínsecas para além do contexto de sua relação, apropriação e transformação mútuas. A partir dessa premissa, procuro aproximar

\footnotetext{
1 Nunca é excessivo insistir na ancoragem histórica, diversas e muitas vezes em violenta disputa acerca do que constitui a "natureza humana" (cf. Sahlins, 2008). No sul da África, uma proeminente forma de registro literário em inglês é o relato que mescla de maneira nostálgica, ora entusiasta, ora crítica, a memória colonial e o testemunho pessoal. Neles, as vicissitudes narradas são protagonizadas por cães dotados de qualidades como generosidade, argúcia e lealdade (Ferreira, 2002; Fitzpatrick, 2010).

2 A noção de terceiro encontra inspiração nos escritos de Charles Peirce (1992), para quem o entendimento resulta de uma relação entre distintas consciências a propósito de um objeto.
} 
analiticamente o frequente recurso aos cães como mediadores e a produção de Si e do Outro como incomensuráveis, inegociáveis, incomunicáveis. Recorro às considerações de Archie Mafeje, para quem o conceito amplamente aceito de alteridade indica o quanto a antropologia, ao estabilizar seu modo de conhecimento sobre essa divisão entre Eu e Outro, a partir de inspirações epistemológicas coloniais, acaba por se restringir à tarefa de taxonomização de um real tornado unívoco, conditio sine qua non para a existência da disciplina em moldes perscrutadores (Borges et al., 2015). Seguindo esse autor, a constatação de um real estabilizado, dotado de propriedades intrínsecas, imutáveis e incontestes, não só não deveria ser nosso objetivo, como deveria ensejar um ímpeto contestador, próprio do que ele chama de ontologia combativa.

As considerações de Mafeje (2001) a tal respeito, somadas à experiência de campo, me levam a afirmar que o expediente aparentemente alheio e distante de aludir aos cães para apreciar os humanos aproxima-se bem mais do que possamos imaginar daquilo que fazem os antropólogos afeitos à noção de alteridade. Por essa razão, parece-nos profícuo entender como no pós-apartheid experiências de racismo e segregação seguem sendo vividas a partir da produção constante de um Outro como criatura bestial, muito amiúde equiparada aos cachorros. Por outro lado, ideais de uma vida isenta de racismo lançam mão dos cachorros para enunciar o quanto o horizonte utópico de tal convivialidade é violentamente solapado, não se tratando, portanto, de um fenômeno instransponível, porque inscrito na "natureza" dos corpos. ${ }^{3}$

\section{Ideais de existência}

Desde 2006, tenho passado em torno de dois meses, anualmente, na África do Sul. Meu lugar naquele país, no entanto, é menos definido por sua localização espacial e mais em termos de ações desenroladas ao longo do tempo. Nesses últimos anos estivemos (outros companheiros de investigação e eu) nos movendo em Kwazulu-Natal, acompanhando nossos anfitriões,

\footnotetext{
Haraway (2004, p. 331) desenvolveu a ideia de "companion animals", a fim de demonstrar como as premissas do ideário humanista e humanitário deveriam ser desestabilizadas: "Dogs confront us with [...] many questions, ethical, ontological, political [...]." Constatação de natureza semelhante encontramos em Le Guin (2014) acerca de seu processo criativo. Para a autora, ao contrário do que se pensa, a ficção científica não alude a tempos ou espaços futuros, mas a possibilidades e inspirações ignoradas, porém presentes, nos mundos em que existimos.
} 
alguns já amigos íntimos, vinculados de forma direta ou indireta ao Landless People Movement (LPM). O LPM preponderantemente congrega em suas bases moradores de fazenda, isto é, ex-trabalhadores que residem em propriedade alheia, onde outrora trabalharam, e que lutam por ter seus direitos de residência nessas mesmas propriedades assegurados. Por essa razão, prefiro definir nossa investigação como um lugar-evento (Borges, 2004), ou seja, como um emaranhado de efeitos, de procedências e trajetórias diversas que não pode ser explicado por uma cadeia causal linear. Como se verá adiante, nessa intrincada composição entrelaçam-se humanos e também animais, em suas apreciações mútuas.

Tenho insistido no fato de que se nós estamos fazendo pesquisa, também nossos anfitriões estão constantemente investigando saídas para seus dilemas cotidianos relacionados à sua luta política de fundo - que é a restituição de terras que lhes foram usurpadas ou das quais ficaram alijados ao longo de mais de um século de deliberações legais do Estado sobre um volume restrito de território destinado a populações não brancas naquele país. ${ }^{4}$ Dito de outro modo, nós somos pesquisadores e as pessoas que nos recebem em suas vidas também o são (Borges, 2009). De alguma maneira, nossas inquietações surgem dessa oportunidade que nos é dada de pesquisar o processo de pesquisa alheio, de observar quais são os problemas que nossos anfitriões se colocam, as soluções que cogitam para essas questões, os caminhos que percorrem em busca da melhor saída para seus dilemas.

Em linhas gerais, para usar um termo palatável (ainda que eivado de dubiedades), podemos dizer que nossos anfitriões têm como problema central em suas vidas a terra, ou em suas terras, a vida. Para esse ponto faço convergir dois feixes de relações que me parecem esclarecedores da imbricação entre noções de terra e de vida ou, em uma palavra, ideais de existência. ${ }^{5}$ Acreditando que haja uma relação entre o que pode ser considerado desejável ou abominá-

\footnotetext{
${ }^{4} \mathrm{Na}$ África do Sul, a categoria "black" tem sido usada para abrigar pessoas que outrora seriam colocadas nos escaninhos estatais como Bantu (hoje, Africans), Coloured (falantes de Afrikaans) e Asian (hoje, Indian). $\mathrm{O}$ sentido contemporâneo, ao mesmo tempo em que alude, contrapõe-se à categoria racista que funcionava como guarda-chuva antes do fim do apartheid: non-white.

5 A partir do que propõe Povinelli (2012), prefiro ideais de existência à vida, para não cair na cilada do humanismo seletivo que impera no que a mesma autora chama de "late liberalism", capaz de se infiltrar e prosperar nas entrelinhas mesmo em escritos que consideramos desafiadores da ordem epistêmica e política hegemônica.
} 
vel e o tipo de vínculo e sentido que as pessoas dão simultaneamente às suas vidas e às suas terras, lançarei mão (i) do romance de J. M. Coetzee (2000), Disgrace, publicado em $1999,{ }^{6}$ e de (ii) ficções etnográficas ${ }^{7}$ extraídas de meu trabalho de campo no país, que tocam em problemas vividos contemporaneamente por pessoas negras nos movimentos de luta por terra, contrários aos privilégios dos brancos.

A história sul-africana é amplamente conhecida através de uma narrativa modernista, linear, evolucionista em larga medida, que detalha as investidas de um conflitivo projeto colonial europeu que deitou raízes naquele território, gradualmente ali instalando um Estado autoritário, cujo princípio central de governo era o racismo. Essa narrativa, por um lado, espelha de modo nítido um longo processo de violência que, a fim de privilegiar os brancos, procurou capturar e imobilizar as populações não brancas daquele país. Ela incorre em dois efeitos perversos que, no entanto, não teria intencionalmente o objetivo de fomentar. Primeiramente, hegemônica - e, ainda assim caricatural, mas que ao fim e ao cabo é a que chega aos nossos ouvidos -, deposita pouca ou nenhuma ênfase na agência, na resiliência, na revolta dos sujeitos não brancos nesse processo de escalada do autoritarismo racista. Em outras palavras, essa narrativa, que se pretende denunciadora, acaba muitas vezes por obliterar as ações de resistências e as negociações violentas em que tomaram parte os não brancos, ao longo dos últimos séculos na atual África do Sul.

Outro aspecto importante quando compramos a narrativa hegemônica por seu valor de face é a suposição de que os sujeitos históricos são os mesmos, independentemente de quem conta a história. Não damos muita importância ao fato de que nós mesmas, quando nos voltamos ao passado, tornamos redivivas disputas transcorridas, imputando-lhes motivações que nascem de

6 A escolha desse romance é proposital. Seu autor foi laureado com o prêmio Nobel de literatura, e essa obra específica foi transformada em um filme hollywoodiano de ampla circulação. A despeito das controvérsias a respeito da literatura de Coetzee na África do Sul, onde o autor é alvo de críticas políticas que identificam racismo em seus escritos, é inegável que sua obra tem uma audiência ampla que, não raro, apenas conhece algo daquele país graças à sua pena.

7 A noção de fiç̧ão etnográfica por mim defendida tem o propósito político e teórico de rechaçar o estatuto da demonstração heurística e das formas de invalidação dos argumentos etnográficos que se ancoram nos princípios de irrefutabilidade da ciência moderna, colonial. O intuito é demonstrar o caráter profícuo da pesquisa minuciosa por ensejar associações analíticas capazes de criar entendimentos ficcionais, isto é, antagônicos a qualquer retorno ou redutibilidade ao "real do mundo". Para uma contribuição que caminha na mesma direção, ver Nyamnjoh (2015).

Horizontes Antropológicos, Porto Alegre, ano 23, n. 48, p. 225-252, maio/ago. 2017 
nossas perspectivas atuais. ${ }^{8}$ Neste último aspecto me deterei brevemente, a fim de (i) entender como, em Disgrace e na vida cotidiana das pessoas negras que conhecemos em Kwazulu-Natal, a terra é um objeto de controvérsia e (ii) refletir sobre a triangulação com os cachorros como forma de ir além da reiteração do racismo, da afirmação da irredutibilidade e da incomunicabilidade em que essas mesmas controvérsias se ancoram.

\section{Sem terra, sem cães}

Uma das personagens centrais de Disgrace é a jovem Lucy, cujo pai de 53 anos fora professor de comunicação em uma universidade sul-africana. No romance, essa jovem branca ${ }^{9}$ busca refúgio no campo, em uma pequena fazenda. Lésbica, vê-se sozinha com os trabalhadores negros da fazenda quando sua companheira se vai. No romance, esse cenário vem à tona quando o pai, David Lurie, viaja ao campo em busca da filha, depois de ter sido afastado de seu posto acadêmico por uma acusação de assédio sexual. Tragicamente, à chegada do pai se segue um assalto à propriedade, com o estupro de Lucy por jovens negros, sendo um deles ao menos "parente" de Petrus, ajudante de Lucy, que a respeito deles diz: "my family, my people" (Coetzee, 2000, p. 201). No ataque, com exceção da bulldog chamada Katy, todos os cães são assassinados: "Dobermanns, German Shepherds, ridgebacks, bull terriers, Rotttweilers. 'Watchdogs, all of them"' (Coetzee, 2000, p. 61) - nenhum kaffir dog entre eles. ${ }^{10}$ No romance de Coetzee, a violência do estupro e a posterior constatação da gravidez de Lucy, assim como sua decisão de dar à luz, compõem um cenário aterrador que emblema o sofrimento de pessoas tanto capturadas pela intolerância, como incansavelmente em busca de saídas desse labirinto (Nashef, 2009).

8 Em um texto já bastante criticado e hoje expandido pelo próprio autor, Mbembe (2002, p. 263) lançava luz sobre o problema das narrativas voltadas a "hipostasiar" a África, especialmente no que concerne à escravidão, colonialismo e apartheid: "By resorting to expedients and failing to address these central questions about life - its forms, its possibilities, and what denies it - African criticism, dominated by political economy and by the nativist impulse, has from the outset inscribed the quest for political identity within a purely instrumental and short-term temporality."

9 Dando vazão artística às ambiguidades próprias da "Nova África do Sul” (Coetzee, 2000, p. 23), no romance praticamente não há menção à "raça". Apenas na página 171, Petrus é definido como "an African".

10 "Kaffir" é um termo derrogatório usado na África do Sul para se insultar africanos negros (black, como esclarecido acima). 
Essa reviravolta no argumento do romance pode evocar diversas interpretações. Dentre elas, menciono apenas duas, plausíveis. Pode ser apontada uma reação especular à voracidade sexual do pai em relação à sua aluna Melanie Isaacs, Melanie-Meláni, "the dark one" (Coetzee, 2000, p. 164). Outra leitura possível recordaria a legislação sul-africana moderna, que proibia o romance, a paixão, o intercurso sexual entre pessoas de raças diferentes, vendo no estupro da mulher branca uma alegoria do sofrimento experimentado por um sem-número de pessoas tolhidas em seus desejos, como propõe Moutinho (2004). ${ }^{11}$

Neste ponto, esclareço que minha solidariedade irrestrita com Lucy não implica desprezo pelos outros personagens desse cenário de dores e conflitos. Para ser mais precisa, refiro-me aqui aos chamados "moradores de fazenda", como talvez o fossem os personagens criminosos do romance, parentes de Petrus, definido assim pelo pai de Lucy: "She has a man who helps sometimes. Petrus. An African" (Coetzee, 2000, p. 171). Em minha pesquisa na região de Kwazulu-Natal, conheci diversas famílias que haviam sido trabalhadoras em fazendas de brancos, isto é, que viviam em terras alheias, vendendo sua força de trabalho geralmente em troca do teto precário que as abrigava. Ao contrário do que se passa no romance, na história sul-africana de padrões modernistas praticamente não há espaço para essas pessoas e suas moradas.

Quando se narra a vida da população negra sul-africana durante o apartheid, dois espaços de segregação são privilegiados: as townships urbanas e as homelands rurais. Havia, entretanto, pessoas, famílias inteiras, que não estavam nem em um lugar nem em outro: não eram proprietários de terra que haviam sido desalojados e colocados à força em cidades, e tampouco viviam em bantustões, em "homesteads" tradicionais sob a batuta de um chefe "tradicional" - não raro em conluio com as autoridades do apartheid que os indicavam para ocupar tais cargos, ora em desacordo, ora com o apoio das comunidades (Ntsebeza, 2005). Esses cativos que trabalhavam em fazendas de

\footnotetext{
${ }^{11} \mathrm{Na}$ história sul-africana, 50 anos de legislação segregacionista explícita coroaram um projeto em que se buscava romper, por distintos e perversos meios, qualquer elo que os colonizadores pudessem haver tido com ancestrais não brancos, garantindo que a Swart Gevaar - a ameaça negra - estaria para sempre banida tanto do interior de seus corpos quanto do alcance de suas vistas. O pai discorda de Lucy, que chama os três homens que invadiram sua fazenda e seu corpo de estupradores. Segundo David, o que eles queriam era "mating", acasalar, colocar uma semente "not the woman not in love but in hatred, mixed chaotically, meant to soil her, to mark her, like dog's urine" (Coetzee, 2000, p. 199, grifo meu).
}

Horizontes Antropológicos, Porto Alegre, ano 23, n. 48, p. 225-252, maio/ago. 2017 
proprietários brancos, obliterados das narrativas mestras, eram outrora mais fáceis de apagar do cotidiano porque era simples livrar-se deles, como reitera Lucy, quando adverte seu pai:

As for Petrus, he is not some hired labourer whom I can sack because in my opinion he is mixed up with the wrong people. That's all gone, gone with the wind $[\ldots]$ Wait until you have heard Petrus's side of the story. (Coetzee, 2000, p. 133).

O fato de se encontrarem nessa fenda, nesse entrelugar pouco explicitado nas narrativas convencionais, ajuda a entender seu parco poder de barganha quando hoje, em tempos democráticos, o assunto é a reparação de violências que sofreram durante o apartheid. ${ }^{12}$ Os moradores de fazenda que conhecemos, organizados em torno do LPM, querem ter uma terra que seja sua - embora jamais tenham sido proprietários, ou seja, jamais tenham tido a titularidade de nada. Sua demanda é considerada absurda aos olhos do observador mais liberal, tendo em vista que atualmente os moradores de fazenda não podem legalmente ser expulsos das casas e do pequeno entorno de terras que circunda suas moradias, localizadas no interior de fazendas de brancos - como alerta Lucy a David.

No entanto, uma coisa é a grande narrativa modernista e as leis que asseguram seu direito de ficar onde estão, e outra é o dia a dia de muitas dessas famílias que se veem constantemente violentadas e gradualmente despejadas de suas casas. A presença de famílias de moradores que já não mais trabalham

12 Moutinho (2004), ao se dedicar ao romance Disgrace, atentando para os enunciados de David Lurie e sua filha, faz uma síntese analítica pertinente acerca do ponto de vista hegemônico sobre o processo de reforma da terra. No romance, Petrus é relembrado como "ajudante" de Lucy. Em outro momento, ela esclarece para seu pai: "In fact, since March, co-proprietor" (Coetzee, 2000, p. 62). A incongruência entre uma afirmação e outra pode ser entendida se considerarmos que, com a ajuda financeira do pai (Coetzee, 2000, p. 60), Lucy comprou a fazenda. Em suma, podemos cogitar que ele fosse um "morador de fazenda", como os ativistas do LPM. No entanto, a licença poética do autor, em harmonia com o senso comum de seu personagem principal, permite que ele sugira a Lucy que "venda a fazenda para Petrus" (Coetzee, 2000, p. 159), como se o "ajudante" tivesse solvência para isso. Como o personagem justifica essa metamorfose vertiginosa de um ajudante em fazendeiro? "Petrus has borrowed a tractor [...] In a matter of hours he has ploughed the whole of his land. All very swift and businesslike; all very unlike Africa. In olden times, that is to say ten years ago, it would have taken him days with a hand-plough and oxen" (Coetzee, 2000, p. 151, grifo meu). Sobre os desafios intrínsecos aos programas de redistribuição de terra e compensação de dívidas históricas em um contexto desenvolvimentista e racista, ver, dentre outros, Ntsebeza e Hall (2006).

Horizontes Antropológicos, Porto Alegre, ano 23, n. 48, p. 225-252, maio/ago. 2017 
para os fazendeiros é considerada especialmente indesejável porque, segundo os últimos, ter moradores negros em suas terras desvaloriza o preço de suas propriedades no mercado. Velhos proprietários ou seus sucessores tentam se livrar a todo custo desses moradores quando desejam vender suas terras. Se não logram fazê-lo, muito frequentemente os novos proprietários, sem vínculos de qualquer ordem com essas pessoas, acabam por expulsá-las definitivamente de suas terras. Em um ou outro caso, as táticas empregadas para que as famílias saiam das terras "espontaneamente" são bastante semelhantes: proíbe-se que as pessoas circulem pelo interior da fazenda, o que impede as crianças de usarem atalhos até a escola ${ }^{13}$ ou os adultos de se deslocarem mais rapidamente à cidade; proíbem-se visitas de seus parentes; proíbe-se que enterrem seus mortos; que visitem os túmulos de seus ancestrais; que colham água; que criem gado; que tenham cães.

A crueldade é pungente, inadmissível e nos deixa com a sensação de estarmos diante de uma suposta humanidade em comum, que se desrespeita, que se agride em termos misóginos, racistas. Para evitar a dolorosa paralisia que nos assalta quando estamos diante de casos de violência tão inaceitáveis, volto meu olhar para a incompatibilidade e o conflito que emergem entre fazendeiros (em sua absoluta maioria, brancos) e os moradores negros que vivem no interior de suas fazendas, tomando os animais como um terceiro (Peirce, 1992). Os animais nos revelam como regimes de construção de Si na África do Sul contemporânea ainda passam, muitas vezes, pelo deslocamento do Outro para um espaço não civilizado. Esse Outro pode ser tanto humano quanto animal. Humanos ou animais podem ser maltratados por serem meras bestas, assim como podem igualmente ser respeitados por serem, em suma, gente, isto é, merecedores de respeito e compaixão. A questão aqui é discutir algumas controvérsias acerca da definição de quais humanos e quais animais são ou não considerados gente. ${ }^{14}$

13 Ao etnografrar a luta dos moradores de fazenda pelo direito ao funeral, dediquei-me a analisar um conflito jurídico entre um fazendeiro branco que sequestrara uma família no interior de sua fazenda, chegando a denunciar e levar a juízo três meninas (de 13, 9 e 6 anos de idade), ao fim condenadas, por terem caminhado de suas casas, pelo interior da fazenda, com o objetivo de chegar à escola onde estudavam (Borges, 2008).

14 No romance de Coetzee, após o massacre dos cães de Lucy, David se envolve com Bev Shaw, amiga de Lucy que tem uma clínica veterinária. Nela, a principal função de David passa a ser proporcionar um fim indolor, sem crueldade, a animais desenganados.

Horizontes Antropológicos, Porto Alegre, ano 23, n. 48, p. 225-252, maio/ago. 2017 


\section{Cães africanos}

O confisco e o encarceramento dos animais são denunciados pelos moradores de fazenda como parte das estratégias usadas pelos fazendeiros brancos para garantir a ironicamente chamada constructive eviction, ou seja, a saída "espontânea" dos moradores negros de suas terras, dado que sua sobrevivência se torna inviável: sem mobilidade, sem água, sem roça, sem animais. ${ }^{15}$ Anteriormente, por se tratar de cabras e vacas, encontrei conforto na literatura para relacionar a indignação dos moradores negros violentados ao fato de tais animais serem fundamentais em suas vidas, um elo entre seu cotidiano mundano e instâncias transcendentais, por assim dizer, presentes não somente na sua nutrição, mas na comunicação ritual com seus ancestrais. ${ }^{16}$

Por outro lado, para os que conhecem a obra de Coetzee, a relação entre humanos e não humanos não é uma novidade. Ao menos em dois de seus livros (A vida dos animais e Elisabeth Costello), essa é a viga mestra de seu argumento. Trago à baila uma vinheta de campo, a fim de aproximar a análise proposta da ficção literária à da ficção etnográfica, a propósito dos animais como terceiro na produção e transformação do preconceito e do racismo. ${ }^{17}$ Embora vacas e cabras sejam onipresentes nas ações e discursos das pessoas com quem fazemos pesquisa na região de Kwazulu-Natal, cães se mostraram uma via privilegiada para entender as questões aqui postas. Lá, como no romance Disgrace, por vezes são os cães os animais violentados.

Um de nossos melhores amigos e o anfitrião mais solícito na África do Sul se chama Mangaliso Khubeka. Ao longo de seus mais de 60 anos, Mangaliso se dedicou a inúmeros afazeres: jogador de futebol, trabalhador fabril, motorista de

15 Toquei tangencialmente nesse assunto ao falar de um conflito entre um morador e o proprietário da fazenda, que tinha como tema o "impounding" de alguns animais do morador (cabras e vacas), confiscados pelo fazendeiro porque os bichos pastavam fora da área delimitada para a família de moradores (Borges, 2010).

16 Kuper (1982) é uma referência clássica, contestada por autores como White (2010) e Guy (2014). No entanto, enquanto o primeiro toma o argumento de Kuper por seu valor de face e atribui sua ineficácia para o entendimento de fenômenos contemporâneos, dadas as mudanças trazidas pelo capitalismo à cultura tradicional, o último recorre a evidências documentais do período colonial para demonstrar a violenta regulação estatal do papel do gado na organização social, ou seja, na produção da cultura. Guy frisa o quanto a contenção e a taxação do rebanho responderam pelo confinamento territorial e pela subordinação de todos, mas especialmente das mulheres, a arranjos de casamento insatisfatórios, sem ancoragem na cosmologia ou na tradição.

17 Pensemos com Haraway (2004), por exemplo, nas confrontações proporcionadas por animais, que temos em clássicos como The island of Doctor Moreau de Wells, ou em Animal farm de Orwell.

Horizontes Antropológicos, Porto Alegre, ano 23, n. 48, p. 225-252, maio/ago. 2017 
van, etc. Nos últimos tempos se tornara a maior liderança do LPM. Por razões diversas, Mangaliso foi gradualmente afastado dessa organização (Rosa, 2011). Concomitantemente ao seu alijamento institucional, Mangaliso conseguiu receber do Estado sul-africano uma fazenda, em resposta a um pleito por reparação (redistribuição) que apresentara junto com alguns de seus familiares, há aproximadamente uma década. Apesar de afastado do movimento, Mangaliso não deixou de lutar pelos direitos dos moradores de fazenda. Em uma de nossas visitas a ele, em janeiro de 2011, já em sua própria fazenda, entre os muitos assuntos que vieram à tona, falamos de seu cachorro, chamado Satan (Satã). ${ }^{18}$ Como sintetiza Suzman (1994, p. 225), a nomeação zulu permite às pessoas "to communicate their feelings indirectly, without overt confrontation and possible conflict". Segundo esta autora, comentários sociais dirigidos à comunidade - e aqui podemos pensar também nos fazendeiros brancos da região - podem assumir a forma de nomes com conotação negativa, como Satã (Suzman, 1994, p. 267). Assim, reconhecendo a importância dos nomes, era inevitável dar-se conta de como lidavam com seus demônios de forma muito peculiar, lembrando que enquanto alguns como eles o trazem para perto de $\mathrm{si}-\mathrm{o}$ caso dos mineiros na Bolívia com El Tío (Taussig, 1980) -, outros o rechaçam. ${ }^{19}$

Em oportunidades anteriores, quando nos aproximávamos da fazenda, Satã costumava ir até o portão principal, em silêncio, um pouco distante, sem demonstrar alarde, como que dizendo: "Estou vendo vocês, vocês estão me vendo?" Naquele dia, porém, enquanto falávamos sobre Satã, ele nos olhava, preso a uma corda. Sabendo da candura de Satã, perguntei a Mangaliso a razão para estar atado. Mangaliso dizia que, apesar de agora ter finalmente sua terra, não podia deixar o cão solto, pois os fazendeiros vizinhos (brancos, e em sua maioria em conflito aberto contra os moradores negros que viviam no interior de suas propriedades ou contra vizinhos fazendeiros negros que, como o próprio Mangaliso, muito recentemente receberam do Estado terras em restituição aos seus pleitos),

${ }^{18}$ Notemos que o nome não somente é algo introduzido pelo colonizador, como comunica ao falante exclusivo de inglês algo que não seria entendido se pronunciado em zulu (Velden, 2013).

19 “'[...] o diabo, chamado por eles de 'cão', é considerado 'chefe' de todos os cachorros que vivem entre os homens", nos diz Velden (2009, p. 131), acerca dos Karitiana. No entanto, como frisa o mesmo autor, as ressalvas em relação ao caráter dos cachorros não os levam a se afastar desses animais: "Os Karitiana projetam sobre os cães características que são, em princípio, não sociais e, em tese, problemáticas para a convivência entre humanos e animais [...] mesmo assim, os cachorros estão lá, em bom número, na aldeia, perfeitamente familiarizados pelos Karitiana e adaptados à vida em 'sociedade"” (Velden, 2009, p. 136-137).

Horizontes Antropológicos, Porto Alegre, ano 23, n. 48, p. 225-252, maio/ago. 2017 
persistiam em sua prática de envenenar ou assassinar os cachorros dos negros. Mangaliso nos disse: "Eles nos odeiam tanto quanto odeiam nossos cachorros."

Azevedo (2013) apresenta em sua tese de doutorado o diálogo que teve com um desses fazendeiros brancos, vizinho de Mangaliso, quando da morte de um dos cães na casa de Mangaliso. O homem veio até a casa e ironicamente perguntou se a família faria um "funeral ritual". A intervenção sarcástica do fazendeiro branco adiciona ao termo "funeral" a qualidade de "ritual", produzindo um discurso relativista por um lado (porque reconhece a cultura alheia) e bestializante por outro (afinal, cães e seus donos compartilham rituais). De acordo com a autora, na ocasião, a apreciação geral foi semelhante à que tivemos quando falávamos de Satã: o fazendeiro produzira com aquelas palavras seu afastamento tanto da família de Mangaliso quanto de seus cachorros. $\mathrm{Ou}$ seja, os lançava no polo das bestas "tradicionais". ${ }^{20}$

Satã é o que a literatura especializada chama de um Canis africanis. Por serem africanos, nativos, cachorros desse tipo nunca foram considerados propriamente "puros" para serem classificados como uma raça. Entendidos como "just a dog", desprezados como párias, tornaram-se conhecidos pela alcunha derrogatória "kaffir dog". No entanto, como demonstram as diversas controvérsias bibliográficas sobre o assunto, mais que qualquer outro, "Africanis is the true dog of Africa". No contexto mais recente de "African Renassaince and heritage creation", como o nomeiam alguns autores, "in a diametrically opposite marketing strategy, the Africanis dog is promoted as completely free of European breed's influence [...] as autochthonous and 'authentic'." (Swart, 2003, p. 193 et passim). É um cachorro que pode ser ágil, mas que normalmente encontra-se languidamente contemplando seu arredor. Que pode acompanhar seu dono na caça ou no pastoreio, advertindo-o da presença de animais predadores ou ameaçadores como um porco-espinho, mas que raramente ataca humanos. Em suma, não é um watch dog como os da personagem Lucy. Considerados "worthless", são misturados com os preferidos greyhound (Swart, 2003, p. 198) para fins mais produtivos. A esses cães africanis, os brancos atribuiriam as mesmas propriedades que aos seus donos negros: "“vicious', 'wretched' and 'uncivilized' [...] animals of lowly status, undisciplined,

${ }^{20}$ Segata (2012) sustenta que o trato com os animais de estimação é facilitado por técnicas e discursos que os afastem de seu "estado natural", ou seja, que os "civilizem". 
uncontrollable and prone to disease" (Tropp, 2002, p. 455-456). Os predicados desses cães, sua endogeneidade, seu conhecimento tácito do território, sua mobilidade, seu desrespeito às fronteiras das propriedades privadas, sua recusa em obedecer a um único propósito na vida, passaram a ser alvo de cerceamento e segregação, como o eram seus donos. Desde o século XIX, há registros de matança em massa dos cães de caça dos africanos, levadas a cabo por oficiais do Estado, a serviço de projetos de conservação de florestas estatais, ou seja, de criação de reservas, planejadas para salvaguardar a propriedade e limitar a mobilidade dos africanos, garantindo assim o "capitalist agriculture's sucess". Cachorros africanos e seus donos, entendidos como "poachers, trespassers, predators and vermin", eram alvo de um "broader onslaught on their lives and livelihoods" (Tropp, 2002, p. 466), que ironicamente se disfarçava por trás de ideários conservacionistas, lançando mão de veneno no extermínio.

Como mencionado em um conhecido livro de Steinberg, Midlands, os fazendeiros brancos na região de Kwazulu-Natal, ao longo de um século, também caçaram esses cães, tentando bani-los e expulsando os moradores de fazenda que os tivessem em suas casas (Steinberg, 2002, p. 225). Não por coincidência, escolho mencionar essa obra. Em seu romance, Steinberg narra o assassinato do filho de um fazendeiro branco na mesma região onde fazemos pesquisa, ocorrido em 1999. O autor, após entrevista com as partes envolvidas e investigação em arquivos, constrói um argumento que tem mais uma vez os animais no centro da cena. $\mathrm{O}$ fazendeiro branco, alegando dificuldades financeiras, proíbe os moradores de sua fazenda de terem suas cabeças de gado, pois necessita ocupar toda a área com sua própria produção. As novas regras são humilhantes demais para os moradores, especialmente para os homens jovens, desempregados, que perdiam, após a decisão do dono da fazenda, sua única chance de conseguir pagar o dote de um casamento. ${ }^{21}$ Essa obra, baseada em pesquisa documental, demonstra como perduram, na atualidade, investidas contra os cães impetradas durante todo o período colonial - como os massacres descritos por Tropp (2002) -, a fim de garantir a constituição de territórios intransponíveis (fazendas privadas, game reserves, etc.), isto é, livres do trânsito de sujeitos que não sejam

${ }^{21}$ Dote conhecido como Ulobola que, como vimos acima, trata-se de uma tradição fortemente informada por políticas coloniais de imobilização dos classificados como não brancos (especialmente os chamados Bantu) e taxação sobre suas casas e rebanhos. 
os proprietários legais dessas terras. ${ }^{22}$ Segundo Mangaliso, e também a partir dos dados coletados por Steinberg, taxar e confiscar o gado ou caçar e matar os cães foi e continua sendo uma forma de assassinar lentamente os negros, sem dúvida distinta daquela adotada por quem invade uma propriedade para torturar e assassinar seus donos (como o vimos ficcionalizado em Disgrace), mas igualmente dolorosa e reveladora das violentas modalidades de intolerância.

\section{Hate speeches}

A história da domesticação dos cães na África do Sul, assim como a atribuição de qualidades por assim dizer "culturais" a eles, pode ser relacionada à emergência de uma noção de propriedade privada da terra sustentada pela compulsória segregação espacial da população não branca daquele país. Embora seja um topos bastante comum na literatura e nos depoimentos orais, não posso negar que eu mesma vi, em diversas ocasiões, fazendeiros levando seus cães nas cabines de suas caminhonetas enquanto os trabalhadores negros eram transportados na parte traseira, ao relento e sem segurança. Pessoalmente, escutei de pessoas brancas que seus cães, por não estarem habituados ao convívio com negros, eram com esses violentos e latiam mais quando uma pessoa negra deles se aproximava. Ainda que muitas pessoas negras tenham cachorros em suas casas - na cidade ou no campo -, as que conheci dizem que o cachorro não deve adentrar o espaço doméstico, o interior da morada.

Essas observações que pessoas negras ou brancas fazem sobre seus cachorros não são declarações universais e perenes. Devem ser observadas e entendidas num contexto de enunciação cujo terceiro é a pessoa branca ou negra no ângulo oposto da triangulação. Voltando a Disgrace, o assassinato dos cachorros é visto como uma crueldade inominável pelo pai de Lucy. Sua indignação e consciência da vilania do massacre crescem ao longo do romance, quanto mais ele se envolve na tarefa de sacrificar animais desacreditados na clínica veterinária da amiga de Lucy (um "animal refuge", cf. Coetzee,

${ }^{22}$ Bevilaqua (2011) chama atenção para a investida contemporânea dos aparatos estatais sobre os cachorros, em especial das instituições que legislam sobre expressões de agressividade e as punem com base em critérios pensados para coagir humanos. A autora demonstra que tais controvérsias indicam o quanto os critérios de inteligibilidade com que nos constituímos como humanos e modernos seguem refratários à transformação. 
2000, p. 72). A suposta diferença entre os dois modos de matar, no entanto, é contestada por uma mulher falante de Xhosa que leva sua cabra para a clínica. Dado o quadro sem esperanças, à dona da cabra é aconselhada uma injeção letal. Ofendida, a mulher deixa a clínica com a cabra em seu colo. Dessa feita, fica no ar o mesmo incômodo, só que às avessas: que tipo de pessoa mataria uma cabra com uma injeção letal e chamaria isso de "quite end" (Coetzee, 2000, p. 83)? Não saberiam que as cabras são animais nascidos para o sacrifício, canais privilegiados para se comunicar com as sombras, com os ancestrais? Aqui não estamos somente diante de uma oposição entre negros e brancos, mas diante de modos em competição de entender o que caracteriza não a humanidade (em um sentido humanista), mas o que compõe aquilo que chamo ideais de existência. ${ }^{23} \mathrm{O}$ pai de Lucy e a dona da cabra compartilham algo. Para ambos, aquele que é capaz de tamanha vilania com os animais não merece ser qualificado como humano. Por meio dos cães (e, eventualmente, de outros animais), as pessoas avaliam suas humanidades.

Além desse, haveria outro lugar discursivo onde homens e cães se aproximam: as palavras de ordem usadas em discursos políticos, especialmente aquelas entoadas nas liberation songs, atualmente classificadas como discursos de ódio (hate speeches) por seus detratores.

Ao menos desde 2010, tem ocupado o centro do debate midiático sul-africano a figura de Julius Malema (líder "jovem”, banido em 2012 do Congresso Nacional Africano (CNA), condenado por "discursos de ódio" e fundador de um novo partido, o Economic Freedom Fighters (EFF), pelo qual é membro do parlamento nacional desde 2014). Malema é notório pelas controvérsias que suscita. Sugeriu nacionalizar algumas empresas privadas, como as mineradoras. Ainda quando membro do CNA, afirmou desconfiar da denúncia de estupro contra o presidente Jacob Zuma, pois a mulher denunciante, Fezeka Kuzwayo, havia tomado café da manhã ao deixar o hotel no dia do crime, o que indicaria seu conforto com a situação. Podem-se mencionar ainda as mais recentes performances de Malema e outros parlamentares do EFF, que passaram a frequentar o parlamento vestindo macacão vermelho e capacete ou guarda-pós e lenços. Com seus

${ }^{23}$ Uma ilustração pungente desse conflito é composta por Krog, Mpolweni e Ratele (2009), em sua investigação sobre o desprezo dos membros do Tribunal de Verdade e Reconciliação para com o depoimento da Senhora Konile, que teve seu filho assassinado por forças clandestinas do aparato estatal no apartheid e testemunhou ter tomado conhecimento do crime por meio de um sonho, no qual uma cabra lhe aparecia de maneira pouco usual, indicando-lhe indubitavelmente a gravidade do ocorrido.

Horizontes Antropológicos, Porto Alegre, ano 23, n. 48, p. 225-252, maio/ago. 2017 
trajes, recordam o massacre dos mineiros de Marikana, a coloração socialista de seu partido e o trabalho doméstico das mulheres negras. Em suas performances, exigem de maneira jocosa que o presidente Zuma, agora seu inimigo, devolva os recursos públicos gastos em sua residência particular ao erário, sendo algumas vezes forçados pela segurança do parlamento a se retirar do recinto. Outra faceta notória de Malema é seu estilo de vida perdulário, criticado por alguns como signo evidente da corrupção que assola o atual governo sul-africano e louvado por outros como emblema das conquistas garantidas pelas políticas promotoras do black economic empowerment. ${ }^{24}$ De tudo isso, o que o traz para este texto é o uso que faz em suas falas públicas de músicas cantadas nos tempos de luta contra o apartheid, entre as quais uma em especial - Ayasab'amagwala. ${ }^{25}$

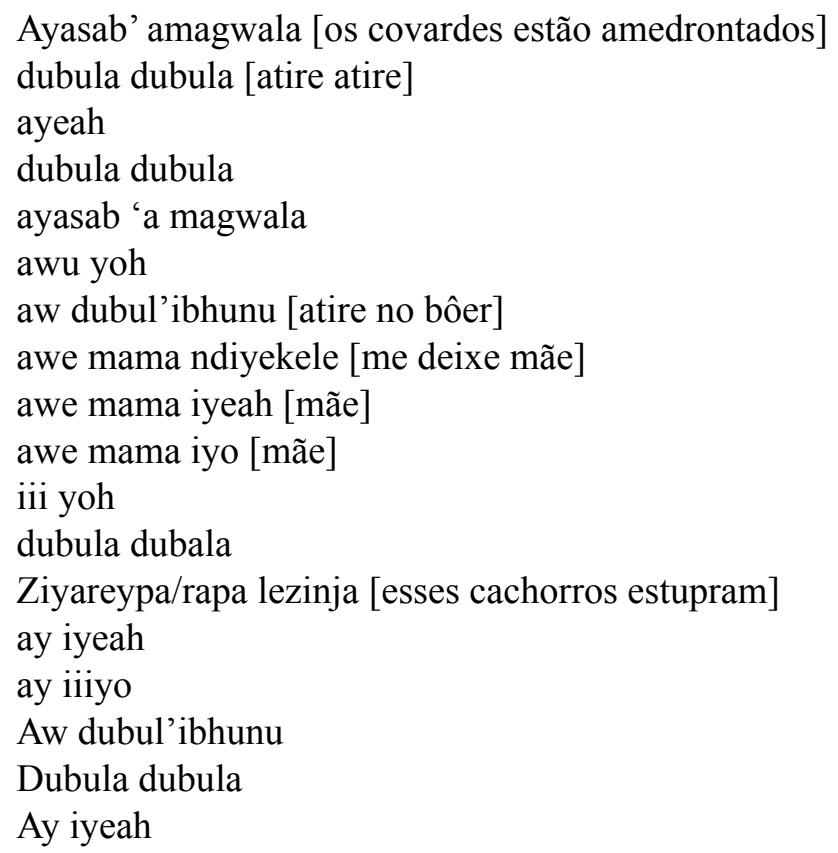

${ }^{24}$ A ambivalência de Malema e seu "consumo conspícuo" têm desafiado os esforços analíticos e os limites morais de diversos cientistas sociais sul-africanos. Dentre outros, ver Posel (2013).

${ }^{25}$ Cherry (2015, p. 236) considera o epíteto hate speech um sinal de "sanitisation of the language of struggle": "The debate culminated in a court challenge by AfriForum representing Afrikaans farmers, to Julius Malema." A performance de Malema foi considerada inconstitucional e, após longa controvérsia, ele saiu condenado. 
Entoada com variações em protestos públicos, a canção acima é amplamente referida como aquela em que se diz "atire nos fazendeiros" (dubul'ibhunu).

Em diversas manifestações políticas das quais participei ao longo dos anos em que tenho ido à África do Sul, especialmente durante funerais que os moradores de fazenda conseguiam realizar a despeito da recusa por parte dos proprietários brancos das terras em que se encontravam as tumbas, escutei canções como essa, de autoria de Peter Mokaba. Porém, talvez por ter presenciado inúmeras atrocidades dos proprietários contra os moradores, nunca me surpreendi com passagens que explicitavam um desejo de "meter bala" nos fazendeiros (-bula, do inglês, bullet). O que sempre me chamou atenção foram versos, como o último desta música de protesto, que diz "ziyareypa lezinja", literalmente, esses cachorros (-inja) estupram (-reypa ou -rapa, do inglês, to rape). Sempre que possível, ou seja, quando a repressão policial não os impede de entoar seus cantos dos tempos da luta contra o apartheid, as pessoas erguem seus punhos e abrem seus pulmões dizendo "amandla, awetu" (que o povo tenha o poder para resistir) e, em meio a pisadas ritmadas no solo ("toyi-toyi"), diversos gritos de guerra como, por exemplo, "fazendeiros são cães" ou outras construções do gênero são entoadas. O termo em zulu "ibhunu", na opinião das pessoas que conheço, falantes dessa língua, refere-se bem mais a fazendeiro do que a bôer ou white, como estabelecido na controvérsia atual em que se viu envolvido Malema. ${ }^{26}$

Minha reflexão nasce de uma experiência etnográfica muito específica que de forma alguma se presta a generalizações; por isso, busco somente sugerir que os diferentes significados atribuídos ao termo - de um e outro lado da querela - nos ajudam a pensar na relação entre humanos e animais, como dobradiça que articula preconceito e convivialidade na África do Sul contemporânea, ensinando-nos sobre meandros pouco evidentes da persistente segregação. Creio que possamos observar essa junção ao menos por duas vias: pela do que é ressaltado e pela do que é obliterado. A ênfase dada à afirmação "vamos atirar nos bôeres" (entendidos como brancos que falam Afrikaans ou latifundiários donos de terras expropriadas das mãos

${ }^{26}$ Em Disgrace, David se surpreende ao encontrar a filha Lucy transformada em uma "solid country woman", a "boervrou" (Coetzee, 2000, p. 60), isto é, uma mulher bôer. 
negras durante o período colonial e do apartheid), acompanhada de uma interpretação incisiva acerca da intolerância explícita ali encerrada, diz muito a respeito de como ainda hoje naquele país são os negros os obrigados a se controlar e a se comportar segundo os preceitos - chamados de democráti$\cos$ - que garantem a integridade dos brancos. Em outras palavras, ao manifestarem seu repúdio àquele verso, os brancos alertam a opinião pública sobre sua vulnerabilidade diante da violência que pode ser cometida contra eles por parte dos negros - como o vimos no romance Disgrace ou em Midlands. Já por meio do verso esquecido pelos debates midiáticos e desconhecido de quem não fala zulu ("esses cães estupram"), uma controvérsia de igual ou pior teor poderia ser fomentada, tendo em vista que o estupro é um tema candente, levantado pela opinião pública daquele país (Gqola, 2016), que caminha in tandem com as reflexões sobre as taxas de disseminação do vírus HIV e de enfermidades relacionadas à AIDS e à vulnerabilidade das mulheres. ${ }^{27} \mathrm{O}$ fato de tal verso não ser mencionado nos debates públicos deixa algumas perguntas no ar: por que não se alude a essa acusação contra os brancos, a que denuncia seu suposto protagonismo em estupros? Não é tal afirmação igualmente detratora e ameaçadora da aclamada harmonia alcançada na Nova África do Sul, após tantas décadas de esforços conjuntos? Se mantivessem o princípio interpretativo referencial que pauta sua análise e rechaço ao verso "dubul'ibhunu", como manifestariam os brancos seu repúdio a uma acusação, tão alegórica quanto a ameaça de balas, de serem cães estupradores?

A exemplo do que se passa quando pessoas são equiparadas a cachorros e vice-versa, podemos constatar uma predileção pelo que será dito, enfatizado (atire nos bôeres) e o que será omitido, ocultado (esses cães estupram). David Lurie, personagem central de Disgrace, assim reflete sobre a incomensurabilidade entre as formas de segmentação do real de que nos fala Leach. O pai de Lucy "would not mind hearing Petrus's story one day. But preferably not reduced to English [...] he is convinced that English in an unfit medium for the

${ }^{27}$ O pai de Lucy, quando investe sobre sua aluna Melanie, o faz a despeito de ela lhe dizer: "No, not now!" Segundo ele, "she does not resist. All she does is avert herself [...]", o que o leva a concluir que não se tratou de um estupro: "Not rape, not quite that, but undesired nevertheless, undesired to the core" (Coetzee, 2000, p. 25). Por sua vez, a respeito dos três jovens negros e de sua filha, David não tem dúvida de que se tratou de um estupro. 
truth of South Africa" (Coetzee, 2000, p. 117). ${ }^{28}$ Em suma, a crítica à música feita por quem condena a incitação ao ódio contra os brancos não alcança esse verso pela ênfase seletiva que orienta a divulgação, especialmente a midiática, daquilo que interessa. Caso houvesse um entendimento generalizado da língua zulu, seria incontornável ressaltar o caráter metafórico ou parabólico da poesia. Como demonstra a literatura especializada, a equiparação de homens a cachorros, com conotação negativa, é recorrente em apreciações que os falantes de zulu têm sobre si mesmos em casos de incesto, como, por exemplo:

If a man (termed umthakathi [...] evil-doer) were to commit incest with his own sister or with a young wife of his father, his own people would rise up against him in horror. The father himself [...] would put "the dog" to death for having thus shamed them $[\ldots]$ the ancestral spirits themselves will inflict punishment. (Krige, 1988, p. 224, grifo meu).

Menos que comparar os bôeres a cães, a constatação (eles estupram) revela uma capacidade de trazê-los para perto de si, de torná-los vis e vulneráveis como qualquer pessoa, sem com isso abdicar da possibilidade de menosprezá-los e de aventar hipóteses para puni-los (atirar neles).$^{29} \mathrm{Em}$ outras palavras, seria pouco razoável não assumir que Peter Mokaba seria uma espécie de bardo (Mafeje, 1967) e que seu ponto de vista sobre os brancos não se trataria de um relato naturalista do real, mas de uma expressão política amparada na licença poética, uma ficção etnográfica.

${ }^{28}$ O trabalho de investigação de Krog, Mpolweni e Ratele (2009) constata que o testemunho da Senhora Konile foi em grande medida desacreditado pela incongruência e pela falta de sentido de suas palavras, traduzidas ao inglês, televisionadas para todo o mundo e registradas nos arquivos do Tribunal de Verdade e Reconciliação. Somente ao recuperar as gravações e transcrições em Xhosa, os autores puderam se dar conta da plausibilidade do que declarava a mãe do rapaz assassinado pelo Estado.

29 Se tomarmos o argumento de Stépanoff (2009) a propósito da metamorfose xamânica no maciço siberiano de Altai, podemos sugerir que a associação de cães a predicados humanistas em nosso caso não implica sua transformação ontológica: cães não deixam de sê-lo, quando à sua identidade se sobrepõe uma humana. Os humanos tampouco deixam de sê-lo quando lhes são atribuídas qualidades animais vis (e.g., cães estupradores). Uma transformação distinta da sobreposição, que prefiro chamar de fusão por subtração, ocorre, no entanto, quando sobre suas vidas se dispõe com um desprezo análogo ao destinado de maneira seletiva a certos animais, em situações particulares (Singh; Dave, 2015). Verifica-se tal transformação por subtração em uma afirmação recorrente nas já mencionadas declarações prestadas majoritariamente por mulheres aos Tribunais de Verdade e Reconciliação: "Meu filho foi morto como um cachorro" (Cabanillas, 2013).

Horizontes Antropológicos, Porto Alegre, ano 23, n. 48, p. 225-252, maio/ago. 2017 


\section{Desfazer a fazenda}

A natureza poética das canções em língua zulu é um consenso entre estudiosos do tema (Erlmann, 1996; Gunner; Gwala, 1994; Sitas, 2004). Intrigada com o fato, perguntei a um amigo se minha interpretação estaria correta. Thabo Manyathi, ativista e ex-pesquisador da Association for Rural Advancement (AFRA), organização não governamental dedicada a apoiar pessoas em luta pela reforma da terra, especialmente moradores de fazenda, sem titubear, me respondeu:

Antonádia,

No. He did not mean really shooting the boer, that's not the real meaning of the song. The song refers to the system of apartheid and oppression and indeed the white farmers were the backbone of that system and they came to represent that system. The farm was and is still the reservoir of racism and apartheid. But I think Malema is just mocking them to serve himself. (grifo meu).

Não me deterei sobre a última afirmação de Thabo acerca dos interesses mais recônditos de Julius Malema, um homem com grandes e evidentes aspirações políticas. Aproveito apenas para recuperar o uso e o sentido atribuído à terra na África do Sul e sua relação com um regime segregacionista que segue apartando homens e mulheres e seus cães entre os que, sim, produzem e os que supostamente não o fazem, sendo os primeiros brancos e os segundos, negros. Penso que convidar Thabo para nossa elucubração ajude a esclarecer muitas das inquietações aqui suscitadas, especialmente as que dizem respeito à persistência do racismo na África do Sul contemporânea.

Diante das nem sempre bem-sucedidas tentativas de restituição de terras na África do Sul nos últimos anos, foi sendo construído um consenso acerca da incapacidade produtiva das famílias negras que receberam terras em reparação a perdas sofridas durante o apartheid e dos riscos que essas transferências de terras acarretariam. As implicações desse raciocínio liberal podem ser vistas no parlamento sul-africano, onde novas leis (acts) de emendas à reforma da terra são constantemente postas em discussão. Novos projetos, voltados para a produção agrícola, distanciam-se de debates preocupados em garantir à população negra soberania sobre a terra que lhes foi usurpada e que reivindicam de volta.

O pensamento governamental na Nova África do Sul não conseguiu desafiar a lógica desenvolvimentista, adepta da ideia de que a terra pertence às 
pessoas, e não o contrário, e, ademais, que a terra (assim como os animais e as pessoas) tem como fim último a produção (Mafeje, 1991). Em tom de júbilo, as associações de fazendeiros (de ababhunu, conforme Thabo) constatam que o governo do Congresso Nacional Africano, quando age razoavelmente, está ao seu lado, senão, atua contra o desenvolvimento. Ao contrário do que sucede atualmente naquele país, no texto ficcional de Coetzee uma saída alternativa se desenrolava a partir da percepção crescente de Lucy acerca de seus privilégios. Se, no início do romance, temos elementos para entender que ela comprou sua fazenda, que Petrus trabalhava para ela como "the dog-man" (Coetzee, 2000, p. 64), quando seu pai retorna para visitá-la, depois do ataque que ambos sofreram, David observa a casa construída por Petrus. ${ }^{30}$ A mesma incompreensão diante da decisão da filha de levar adiante a gravidez e de aceitar a oferta de Petrus para adotar a ela e ao bebê o assalta por completo quando ela cogita "sign the land over to him. I will become a tenant on his land" (Coetzee, 2000, p. 204).

Perplexidade semelhante à de David diante da proposta de Lucy constitui o pano de fundo que sustenta a afirmação feita por Thabo. Segundo ele, seu combate e o dos moradores de fazenda seguem sendo contra o que representa o ibhunu/boer/white farmer. Lutam para pôr fim à violência física e à discriminação ideológica acerca de sua incapacidade atávica e da de seus animais (cães, cabras, etc.) para a terra, sob seus pés e em suas mãos. Lutam para que os fins e sentidos dados à terra pelos negros não sejam mais obliterados e atacados como ilegítimos ou anacrônicos.

O preconceito e o menosprezo de certos brancos por um negro inespecífico, tomado como incapaz - seja por sua bestialidade ou por sua irracionalidade/improdutividade -, ainda imperam nas entrelinhas dos debates públicos naquele país. Esse juízo subjaz, mesmo que de modo tangencial, ao sentimento de vulnerabilidade que assola muitas pessoas brancas (não necessariamente ababhunu, no sentido dado por Thabo) incapazes de reconhecer a relação assimétrica, de violentas raízes coloniais, a amparar o racismo explícito e a ética liberal dos que seguem identificando a terra essencialmente como um meio de produção. Ao apostar no desenvolvimento econômico de matriz modernista e sua noção específica de existir para o mercado, essa perspectiva que se crê

30 "Petrus house has become a reality. Grey and featureless, it stands on an eminence east of the old farmhouse" (Coetzee, 2000, p. 197). 
democrática e pluralista continua a excluir e a apartar de seu campo de relações homens e mulheres negras, moradores de fazendas, trabalhadores rurais e, não nos esqueçamos, seu Canis africanis - uns e outros necessariamente entendidos como objetos no liberalismo tardio (Povinelli, 2012).

\section{Consideracõos finais}

Para encerrar, retomo a analogia entre essa forma de segregar os razoáveis dos imprestáveis, os merecedores de afeto dos desprezíveis, para pensar nos desafios que ainda assaltam muito da antropologia, na medida em que formas hegemônicas de produção de conhecimento nessa disciplina ancoram-se no estabelecimento de divisões e hierarquias e atentam para as propriedades ressaltadas de unidades discretas e separadas, não raro obliterando os interstícios de que nos falara Leach. Em que medida a alteridade como pedra angular de nossa epistemologia não se assenta sobre um conceito excludente de humanidade, todavia amparado em um ideário racista de modernidade?

O experimento reflexivo que proponho neste texto voltou-se para essa difícil questão, para a problematização da separação entre Eu e Outro. Em minha experiência de campo na África do Sul ou nas páginas de literatura aqui mencionadas, vemos que, ao aludir aos cães para apreciar os humanos, as pessoas demonstram um fazer etnográfico distinto daquele que normalmente se propõe. Se, em uma primeira mirada, revelam intolerância e racismo, demonstram igualmente um modo de conhecer e de enunciar tal conhecimento que se ampara não na autoridade exclusiva de quem conhece, classifica e demarca a diferença. A triangulação que se produz entre pessoas e animais desestabiliza a onisciência humanista na qual irrefletidamente nos fiamos. Embora antropólogos possam considerar seu modo de conhecer mais simétrico, a desatenção ao que está no intervalo entre Eu e Outro (no interstício) não deixa de se sustentar na pressuposição de superioridade e, não raro, na isenção de sua/ nossa perspectiva analítica. Protegidos pelo escudo de uma possível ciência, julgamos que racistas são os outros, perdendo assim a oportunidade de refletir sobre a violência intrínseca à atuação dos que detêm o monopólio da análise, da classificação, em uma palavra, da segregação. Em suma, creio que tal mal-estar deveria servir para que antropólogos pudessem se transformar, não mais se arvorando privilégios pelo fato de serem semelhantes em sua produção de (menosprezo pela) diferença. 


\section{Referências}

AZEVEDO, A. Mulheres de Zuluness: casa e casamento entre a família Khubeka falante de isiZulu na África do Sul. 2013. Tese (Doutorado em Antropologia Social)-Instituto de Ciências Sociais, Universidade de Brasília, Brasília, 2013.

BEVILAQUA, C. B. Normas jurídicas e agências não humanas: o caso dos cães perigosos. Avá, Tucumán, n. 19, p. 199-225, 2011.

BORGES, A. Tempo de Brasília: etnografando lugares-eventos da política. Rio de Janeiro: Relume Dumará, 2004.

BORGES, A. À Corte: notas etnográficas sobre conflitos fundiários na África do Sul. In: KANT DE LIMA, R. et al. (Org.). Reflexões sobre Segurança Pública e Justiça Criminal numa perspectiva comparada. Brasília: Secretaria Especial dos Direitos Humanos, 2008. p. 192-199.

BORGES, A. Explorando a noção de etnografia popular: comparações e transformações a partir dos casos das cidades-satélites brasileiras e das townships sul-africanas. Cuadernos de Antropología Social, Buenos Aires, n. 29 , p. $23-42,2009$.

BORGES, A. Uma propriedade, diversas propriedades: etnografia, comparação e a distribuição de benefícios públicos no Brasil e na África do Sul. In: NEIBURG, F. et al. (Org.). Brasil em perspectiva. Rio de Janeiro: 7Letras, 2010. p. 10-30.

BORGES, A. et al. Pós-antropologia: as críticas de Archie Mafeje ao conceito de alteridade e sua proposta de uma ontologia combativa. Sociedade e Estado, Brasília, v. 30, n. 2, p. 347-369, 2015.

CABANILLAS, N. Incorporando la nación: mujeres africanas ante la comisión de verdad y reconciliación sudafricana. Nómadas, Bogotá, n. 38, p. 99-113, 2013.

CHERRY, J. Emzabalazweni. Singing the language of struggle, past and present. In: DEDAIĆ, M. N. (Ed.). Singing, speaking and writing politics: South African political discourses. Amsterdam: John Benjamins, 2015. p. 221-245. 
COETZEE, J. M. Disgrace. London: Vintage Books, 2000.

ERLMANN, V. Nightsong: performance, power, and practice in South Africa. Chicago: The University of Chicago Press, 1996.

FAVRET-SAADA, J. Les mots, la mort, les sorts: la sorcellerie dans le Bocage. Paris: Gallimard, 1977.

FERREIRA, A. Zulu dog. New York: Straus and Giroux, 2002.

FITZPATRICK, P. Jock of the Bushveld. Cape Town: Alinea, 2010.

GQOLA, P. D. Rape: a South African nightmare. Johannesburg: Jacana, 2016.

GUNNER, E.; GWALA, M.(Ed.). Musho!: Zulu popular praises. Johannesburg: Wits University Press, 1994. (African Historical Sources Series).

GUY, J. Colonial transformations and the home. In: HEALY-CLANCY, M.; HICKEL, J. Ekhaya: the politics of home in KwaZulu-Natal. Durban: UKZN Press, 2014. p. 23-47.

HARAWAY, D. The Haraway reader. London: Routledge, 2004.

KRIGE, E. J. The social system of the Zulus. Pietermaritzburg: Shuter \& Shooter, 1988.

KROG, A.; MPOLWENI, N.; RATELE, K. There was this goat: investigation the Truth Comission Testimony of Notrose Nobomvu Konile. Durban: University of Kwazulu-Natal Press, 2009.

KUPER, A. Wives for cattle: bridewealth and marriage in Southern Africa. London: Routledge \& Kegan Paul, 1982.

LAW, J. After method: mess in social science research. New York: Routledge, 2004.

LEACH, E. Animal categories and verbal obscenities. In: HUGH-JONES, S.; LAIDLAW, J. (Ed.). The essential Edmund Leach: vol I. New Haven: Yale University Press, 2000. p. 324-343. 
LE GUIN, U. K. Keynote. 8 maio 2014. Palestra proferida. Disponível em: $<$ https://vimeo.com/97364872>. Acesso em: 28 maio 2016.

MAFEJE, A. The role of the bard in a contemporary African community. Journal of African Languages, v. 6, parte 3, p. 193-223, 1967.

MAFEJE, A. The theory and ethnography of African social formations: the case of the interlacustrine kingdoms. Dakar: Codesria, 1991.

MAFEJE, A. Anthropology in post-independence Africa: end an era or the problem self-redefinition. Nairobi: Heinrich Boll Foundation, 2001.

MBEMBE, A. African modes of self-writing. Public Culture, Durham, v. 14, n. 1, p. 239-273, Winter 2002.

MOUTINHO, L. "Raça", sexualidade e gênero na construção da identidade nacional: uma comparação entre Brasil e África do Sul. Cadernos Pagu, Campinas, n. 23, p. 55-88, jul./dez. 2004.

NASHEF, H. A. M. The politics of humiliation in the novels of JM Coetzee. London: Routledge, 2009.

NTSEBEZA, L. Chiefs and the politics of the land in South Africa. Leiden: Brill, 2005.

NTSEBEZA, L.; HALL, R. (Ed.). The land question in South Africa: the challenge of transformation and redistribution. Johannesburg: HSRC Press, 2006 .

NYAMNJOH, F. Incompleteness: frontier Africa and the currency of conviviality. Journal of Asian and African Studies, Leiden, v. 50, n. 2, p. 1-18, 2015 .

PEIRANO, M. Temas ou teorias? O estatuto das noções de ritual e de performance. Campos, Curitiba, v. 7, n. 2, p. 9-16, 2006.

PEIRCE, C. S. The doctrine of chances. In HOUSER, N.; KLOESEL, C. (Ed.). The essential Peirce: volume 1. Bloomington: Indiana University Press, 1992. p. 142-154. 
POSEL, D. The ANC youth league and the politicisation of race in South Africa. Thesis Eleven, London, v. 115, n. 1, p. 58-76, 2013.

POVINELLI, E. The will to be otherwise/the effort of endurance. The South Atlantic Quarterly, Durham, v. 111, n. 3, p. 453-475, 2012.

ROSA, M. Mas eu fui uma estrela do futebol! As incoerências sociológicas e as controvérsias sociais de um militante sem-terra sul-africano. Mana, Rio de Janeiro, v. 17, n. 2, p. 365-394, 2011.

SÁ, G. Afinal, você é um homem ou é um rato? Campos, Curitiba, v. 14, n. 1/2, p. 243-259, 2013.

SAHLINS, M. The Western illusion of human nature with reflections on the long history of hierarchy, equality and the sublimation of anarchy in the West, and comparative notes on other conceptions of the human condition. Chicago: Prickly Paradigm Press, 2008.

SEGATA, J. Os cães com depressão e os seus humanos de estimação. Anuário Antropológico, Brasília, v. 2011/2, p. 177-204, 2012.

SINGH, B.; DAVE, N. On the killing and killability of animals. Nonmoral thoughts for the anthropology of ethics. Comparative Studies of South Asia, Africa and the Middle East, Durham, v. 35, n. 2, p. 232-245, 2015.

SITAS, A. Voices that reason: theoretical parables. Johannesburg: Unisas, 2004.

STEINBERG, J. Midlands. Jeppestown: Jonathan Ball, 2002.

STÉPANOFF, C. Devenir-animal pour rester-humain. Logiques mythiques et pratiques de la métamorphose en Sibérie méridional. Images Re-vues, Paris, n. 6, 2009. Sem paginação.

SUZMAN, S. Names as pointers: Zulu personal naming practices. Language in Society, Cambridge, v. 23, n. 2, p. 253-272, 1994.

SWART, S. Dogs and dogma: a discussion of the socio-political construction of Southern African dog "breeds" as a window on social history. South African Historical Journal, Pretoria, v. 48, n. 1, p. 190-206, 2003. 
TAUSSIG, M. The devil and commodity fetishism in South America. Chapel Hill: University of North Carolina Press, 1980.

TROPP, J. Dogs, poison and the meaning of colonial intervention in the Transkei, South Africa. Journal of African History, New York, v. 43, n. 3, p. 451-472, 2002.

VELDEN, F. F. V. Sobre cães e índios: domesticidade, classificação zoológica e relação humano-animal entre os Karitiana. Avá, Tucumán, n. 15, p. 125-143, 2009.

VELDEN, F. F. V. “A gente chama de qualquer jeito". Notas sobre a onomástica dos animais de criação entre os Karitiana, Rondônia. Revista Anthropológicas, Recife, v. 24, n. 1, p. 15-43, 2013.

WHITE, H. Outside the dwelling of culture: estrangement and difference in postcolonial Zululand. Anthropological Quarterly, Washington, v. 83, n. 3, p. 497-518, 2010.

Recebido em: 30/05/2016

Aprovado em: 01/03/2017 